\title{
PENERAPAN TEKNOPRENEURSHIP PADA PROSES PENGAWETAN BAMBU UNTUK SEKTOR USAHA KECIL MENENGAH
}

\author{
Santo Ajie Dhewanto \\ Jurusan Teknik Mesin, Fakultas Teknologi Industri, Universitas Islam Indonesia \\ Jalan Kaliurang Km. 14,5 Sleman, Yogyakarta 55501 \\ E-mail :santo.ajie@uii.ac.id
}

\begin{abstract}
Bamboo is a new favourite material in the world of eco buildings in Indonesia. Design innovation of buildings will impact the high demand for bamboo that must be balanced with the rate of production in preserved bamboo supply. Existing problems in small and medium enterprises will be overcome by applying technopreneursip. Among them is by developing the tools that will help in improving the production. The application of technology must be balanced with education to small medium enterprises owner and the labor. Preservation by the boucherie-morisco method can increase production by the same amount of labor and time by 2.8 times than Vertical Soak Diffusion Method. Technologically supported enterprises will further strengthen the bargaining position in the bamboo supply business. The partnership pattern between academia and small and medium business sector will create synergy in developing technopreneurship in Indonesian grassroots.
\end{abstract}

Keywords : Bamboo, Technopreneur, Preservation.

\section{PENDAHULUAN}

\subsection{Pemanfaatan Bambu}

Pemanfaatan bambu di Indonesia dalam satu dasa warsa ini semakin meningkat pesat. Dengan adanya perkembangan teknologi untuk memanfaatkan bambu mendorong para arsitek untuk mengeksplorasi bambu untuk bangunan-bangunan megah. Beberapa bangunan yang menjadi kiblat pemanfaatan teknologi bangunan bambu di Indonesia diantaranya adalah Green School yang berada di Badung Bali, ditunjukkan pada gambar 1. Great Hall Eco Campus Outward Bound Indonesia yang berada di Purwakarta Jawa Barat ditunjukkan pada gambar 2 berikut ini.

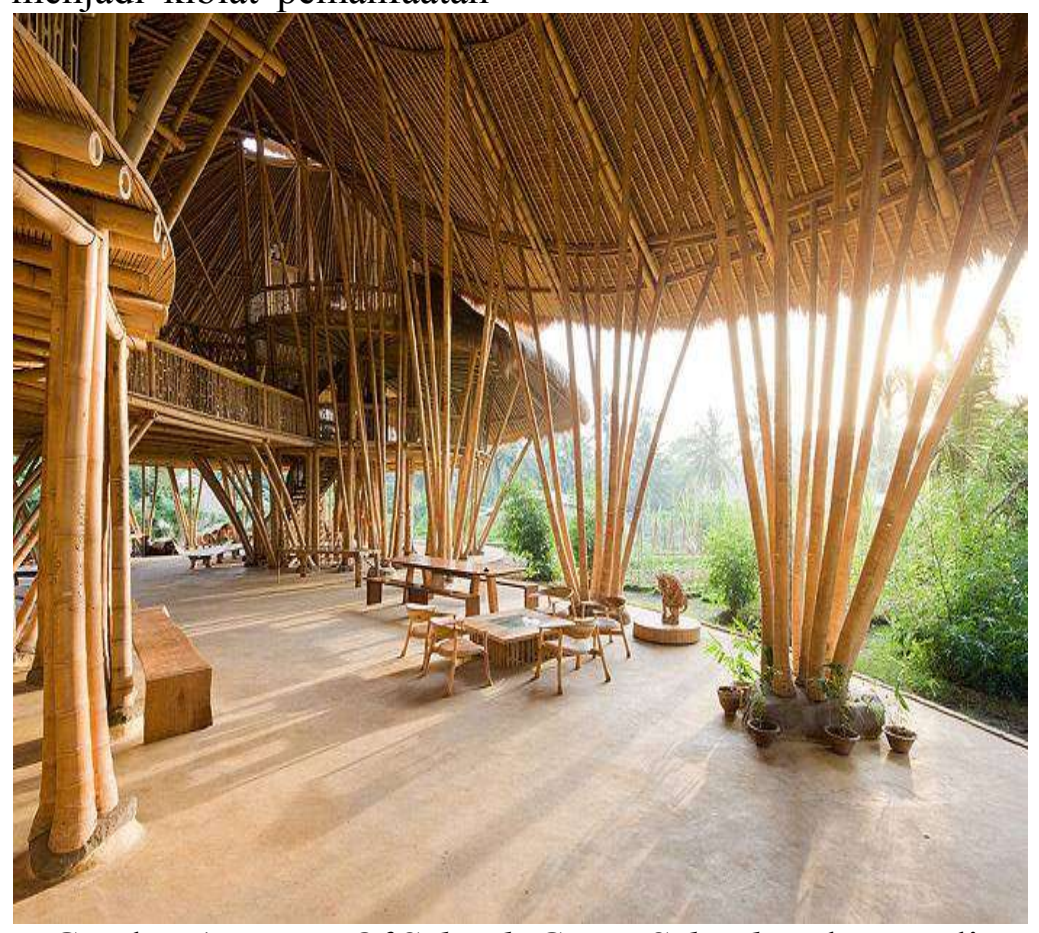

Gambar 1. Heart Of School, Green School Badung Bali. 
Bangunan - bangunan tersebut telah menggugah hati dan membuka mata banyak orang bahwa bambu bisa untuk dimanfaatkan sebagai material utama untuk bangunan yang megah dan produk yang tidak murahan. Untuk mendukung perkembangan kebutuhan akan bambu dibutuhkan bahan bambu dengan kualitas yang baik. Kualitas bambu yang baik diantaranya ditentukan oleh keawetannya. Dalam menyediakan bambu untuk bangunan, kendala yang terjadi di lapangan adalah kecepatan dalam proses pengawetan. Kendala tersebut disebabkan karena beberapa metode pengawetan memiliki karakteristik dan tingkat kesulitan yang beragam.

\subsection{Produksi}

Penentuan harga pokok produksi atau disingkat HPP yang tepat menjadi sangat penting bagi usaha kecil menengah (UKM) karena akan menentukan pendapatan terkait dengan keuntungan yang akan diperoleh para pelaku usaha. Komponen pembentuk keuntungan adalah pendapatan yang diperoleh dari hasil penjualan produksi dan jasa yang dihasilkan oleh perusahaan. Biaya sering juga disebut sebagai pengorbanan yang harus dikeluarkan oleh perusahaan untuk produksi yang pada akhirnya akan menghasilkan suatu barang dan jasa. Biaya tersebut adalah biaya harga pokok atau harga pokok produksi (Mulyadi, 2000).

Perhitungan harga pokok produksi idealnya didasarkan pada penggolongan dan pengumpulan, juga disesuaikan dengan harga pokok produksi di dalam perusahaan. Untuk menentukan harga pokok produksi, perusahaan membutuhkan informasi mengenai bahan baku, biaya tenaga kerja dan biaya overhead pabrik (Mulyadi, 2005).

Dalam menetapkan harga pokok produksi biasanya dilakukan dengan cara menekan biaya produksi serendah mungkin dan tetap menjaga kualitas dari barang atau produk yang dihasilkan, sehingga harga pokok produk satuan yang dihasilkan perusahaan lebih rendah dari yang sebelumnya. Terkait dengan proses pengawetan bambu pada penelitian ini, biaya yang akan coba ditekan adalah biaya tenaga kerja dilakukan dengan mengefektifkan kinerjanya dengan penggunaan alat - alat produksi baru. Selain itu percepatan waktu dalam proses juga diyakini akan mempengaruhi komponen harga pokok.

\subsection{Pengawetan Bambu}

Pengawetan bambu merupakan suatu prosedur yang harus dilakukan sebagai penunjang produk berbahan bambu dan kayu. Pengawetan adalah suatu proses memasukkan bahan pengawet ke dalam kayu atau bambu dengan tujuan untuk memperpanjang masa pakai kayu (SNI 03-32331998). Tanpa dilakukuan proses pengawetan bambu akan mudah terserang kumbang bubuk. Permasalahan ini terjadi karena bambu mengandung zat pati atau amilum yang cukup tinggi. dari komponen utama kimia yang ada dalam bambu terdiri dari selulosa sebesar $40 \%$, hemiselulosa $25 \%$, dan lignin $25 \%$. Komponen minor yang terlarut dalam air yaitu gula, pati, tanin, wax dan garam inorganik, dan kandungan abu 1 5\% (Liese \& Satish, 2003).

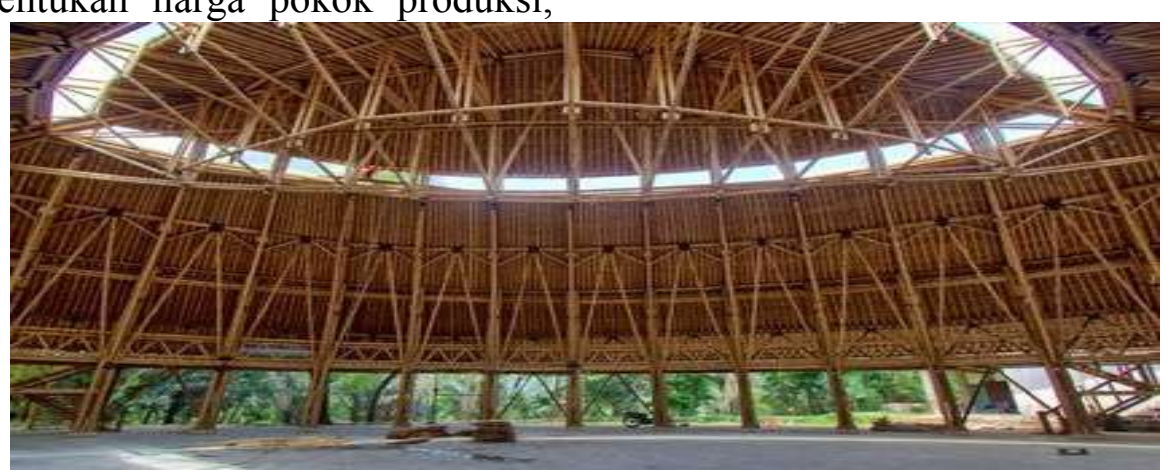

Gambar 2. Great Hall Eco Campus, Outward Bound Indonesia Purwakarta Jawa Barat. 
Pengawetan bambu ada beberapa macam diantaranya adalah cara tradisional yaitu dengan perendaman di sungai. Perendaman bambu dengan air yang mengalir akan menyebabkan terjadinya proses fermentasi pada zat pati di dalam bambu, hasil fermentasi ini akan larut di dalam air, tetapi amilum yang terkandung dalam bambu juga merupakan zat yang menentukan kokohnya ikatan antar serat pada bambu, dengan turunya kandungan zat pati tentu akan berakibat turunya kekuatan bambu (Sulthoni A, 1998).

Selain perendaman pada air yang mengalir juga dikenal pengawetan sistem rendam dengan bahan kimia, tetapi cara tersebut membutuhkan biaya yang besar untuk pengadaan bahan kimia dan juga kurang ramah lingkungan karena banyak bahan kimia yang tidak terpakai nantinya akan terbuang dan membahayakan lingkungan. Cara lain adalah dengan memasukkan zat kimia secara langsung ke dalam daging bambu, cara ini kan lebih efektif jika memasukkan cairan dengan tekanan. Pengawetan bambu di Indonesia bisa dikelompokkan menjadi dua yaitu tradisional dan modern, meskipun masyarakat juga melakukan perbaikan dengan metode trial-error dengan bahan kimia dan bahan alam yang juga dipakai dalam pengawetan kayu. Namun perlu juga dilakukan kajian biaya lingkungan yang disebabkan beberapa metode pengawetan bambu dan penggunaan bahan pengawet kimiawi (Zuraida \& Larasati, 2015).

\section{METODE PENELITIAN}

Penelitian dilakukan di Rosse Bambu, dusun Gentan Margoagung Seyegan Sleman. Pengawetan yang dilakukan di Rosse Bambu menggunakan metode Vertical Soak Diffusion VSD. Kendala penggunaan metode Vertical Soak Diffusion VSD antara lain adalah waktu yang dibutuhkan untuk pengawetan yang relatif cukup lama. Untuk mengawetkan bambu dibutuhkan waktu minimal 14 hari, hal tersebut terjadi karena hanya memanfaatkan gaya gravitasi untuk memasukkan cairan pengawet ke dalam bambu yang diberdirikan pada menara pengawetan, biaya pembuatan menara yang cukup mahal juga menjadi kendala dalam usaha ini.

Selain itu menuntut penambahan cairan setiap hari sehingga tenaga kerja harus naik ke atas menara untuk menambahkan cairan pada setiap bambu, hal tersebut juga membutuhkan tenaga kerja yang berani dan sanggup untuk melakukan pengisian di atas menara yang tidak terlepas dari resiko pekerjaan di ketinggian. Sehingga proses bisnis yang terjadi dinilai kurang efektif karena waktu tunggu yang lama dan kemampuan pemenuhan permintaan pasar yang rendah. Penelitian ini akan mengganti metode VSD dengan metode Boucherie Morisco modifikasi. Menara pengawetan bambu ditunjukkan pada gambar 3 berikut ini.

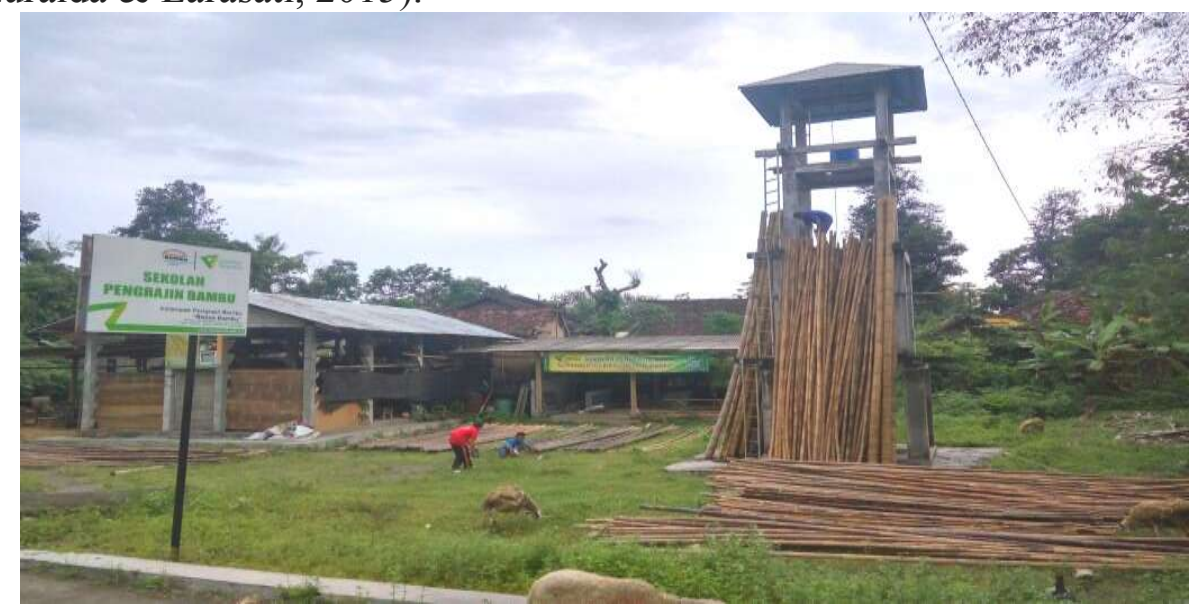

Gambar 3. Menara pengawetan dengan metode Vertical Soak Diffusion (VSD). 
Dalam mendukung kegiatan ini perlu sentuhan technopreneurship agar hasilnya sesuai dengan harapan. Wujud sentuhan technopreneurship antara lain adalah dengan mengembangkan dan menerapkan teknologi yang berkelanjutan diantaranya dengan melakukan modifikasi peralatan. Modifikasi yang telah dilakukan adalah memperbaiki nosel pengawetan bambu sehingga kendala waktu pemasangan yang terjadi pada alat sebelumnya bisa teratasi.

Hal tersebut merupakan kendala yang sebelumnya sering terjadi pada proses pengawetan Boucherie- Morisco. Selain itu juga akan menggunakan alat pembuat alur dalam untuk jalur cairan, sebelumnya dikerjakan secara manual menggunakan pahat tangan, sehingga membutuhkan waktu yang lebih lama juga dalam proses. Tujuan dari penggunaan alat tersebut adalah untuk meningkatkan produktifitas dan kinerja pengawetan bambu, agar diperoleh hasil yang maksimal dan bisa memenuhi permintaan pasar.

Pada penelitian ini akan meninjau ulang dan membandingkan tingkat kesulitan pada proses pengawet-an metode Vertical Soak Diffusion (VSD) dengan Injeksi Cairan menggunakan alat Boucherie - Morisco Modifikasi. Membandingkan hasil maksimal pada metode VSD dan metode Boucherie Morisco modifikasi. Menghitung upah tenaga kerja untuk proses pengawetan dengan metode Boucherie - Morisco modifikasi.

\section{HASIL \& PEMBAHASAN}

Kapasitas produksi dengan keterbatasan menara yang dimiliki yaitu satu menara dalam dua pekan maksimal hanya menghasilkan 400 batang bambu petung dengan diameter rata-rata $13 \mathrm{~cm}$ atau bambu apus dengan diameter rata-rata $7 \mathrm{~cm}$ sebanyak 800 batang. Sehingga dalam satu bulan kapasitas produksi maksimal adalah sebesar 800 batang bambu petung atau 1600 batang bambu apus. Tenaga kerja yang dibutuhkan untuk proses pengawetan terbagi menjadi 3 proses pekerjaan, yaitu pencacahan, memberdirikan dan pengisian cairan di atas menara. Pada penggunan alat ini pekerjaan dibagi menjadi empat yaitu pembuatan alur dalam sebagai pengganti pencacahan, pemasangan dan pengisian cairan, dan pengkondisian bambu.

Pembuatan jalur cairan pada proses pengawetan bambu selama ini dilakukan dengan membuka lapisan lilin yang berada pada kulit bagian dalam bambu. Pembukaan lapisan itu dilakukan dengan pahat kayu. Kekurangan dari cara ini adalah ujung bambu bagian dalam akan rusak dan tidak bisa dimanfaatkan untuk produk lain kecuali sebagai arang. Pembuatan alur dengan cara sebelumnya ditunjukkan pada gambar 4 dan gambar 5 berikut ini.

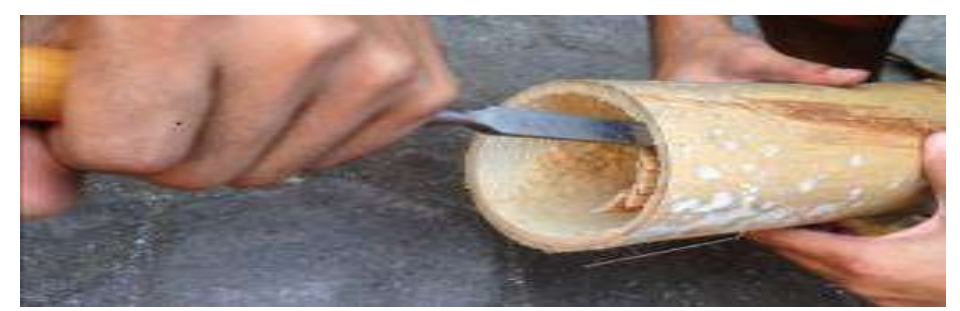

Gambar 4. Pembuatan Jalur Cairan Cara Manual.

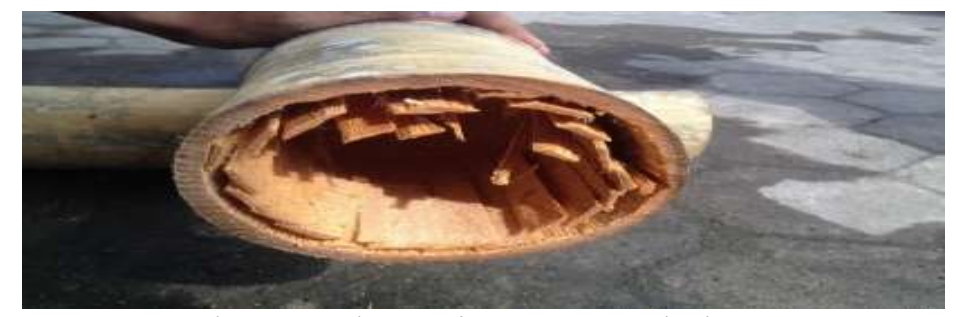

Gambar 5. Jalur Cairan Cara Sebelumnya. 
Tabel 1. Waktu Pembuatan Alur

\begin{tabular}{|c|c|c|c|c|c|c|c|}
\hline \multirow{2}{*}{ No } & \multirow{2}{*}{$\begin{array}{c}\text { Panjang } \\
(\mathrm{mm})\end{array}$} & \multicolumn{2}{|c|}{$\begin{array}{l}\text { Diameter Luar } \\
(\mathbf{m m})\end{array}$} & \multicolumn{2}{|c|}{$\begin{array}{l}\text { Tebal Daging } \\
\text { Bambu (mm) }\end{array}$} & \multirow{2}{*}{$\begin{array}{c}\text { Hasil } \\
\text { Pemahatan } \\
(\mathbf{m m})\end{array}$} & \multirow[t]{2}{*}{$\begin{array}{l}\text { Waktu } \\
\text { (menit) }\end{array}$} \\
\hline & & Pangkal & Ujung & Pangkal & Ujung & & \\
\hline 1 & 3700 & 121 & 103,7 & 12,3 & 10,2 & $2-3$ & 3,27 \\
\hline 2 & 3500 & 121 & 103,7 & 12,3 & 10 & $2-3$ & 3,53 \\
\hline 3 & 3500 & 130 & 106,3 & 12,1 & 10,6 & $2-3$ & 3,12 \\
\hline 4 & 3600 & 125 & 104,6 & 12,4 & 10,5 & $2-3$ & 3,42 \\
\hline 5 & 3500 & 130 & 107,2 & 13,2 & 11,3 & $2-3$ & 2,52 \\
\hline 6 & 3760 & 137 & 112,5 & 13,5 & 11,6 & $2-3$ & 3,49 \\
\hline 7 & 3500 & 125 & 104,6 & 12,4 & 10,8 & $2-3$ & 3,51 \\
\hline 8 & 3600 & 132 & 107,3 & 13,6 & 11,4 & $2-3$ & 3,16 \\
\hline 9 & 3500 & 126 & 104,2 & 12,4 & 10,3 & $2-3$ & 3,14 \\
\hline 10 & 3750 & 136 & 112,6 & 13,3 & 11,2 & $2-3$ & 3,28 \\
\hline \multicolumn{7}{|c|}{ Rerata } & 3,34 \\
\hline
\end{tabular}

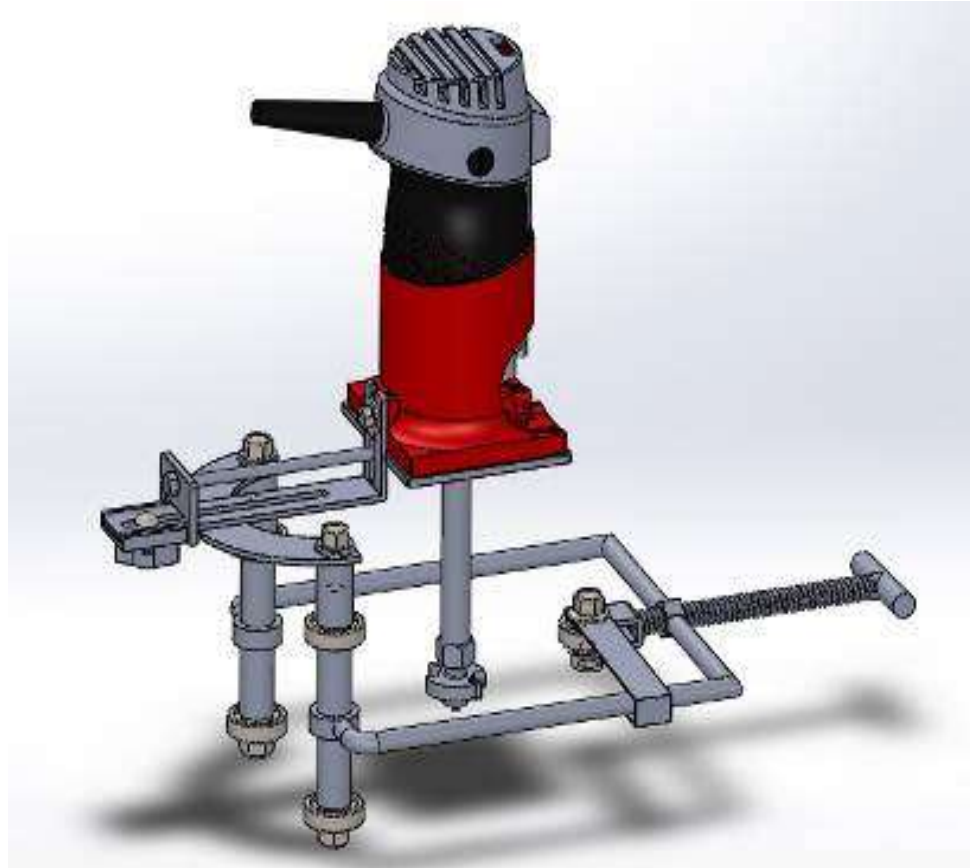

Gambar 6. Alat Pembuat Alur Dalam Bambu.

Alat pembuat alur bambu dikembangkan di Teknik Mesin Universitas Islam Indonesia dengan tujuan untuk memperbaiki waktu pembuatan jalur cairan pada bambu, selain itu juga untuk meningkatkan manfaat dari bahan bambu agar bisa dimanfaatkan secara maksimal.
Alat tersebut menggunakan mesin router yang sudah banyak digunakan masyarakat untuk pembuatan profil pada kayu, kemudian ditambahkan mekanisme pencekam dan handle untuk mempermudah kerja operator. Alat Pembuat alur tersebut ditunjukkan pada gambar 6 . 
Dengan penggunaan alat pembuat alur bambu tersebut menurunkan kemungkinan pecahnya bambu saat proses pengawetan karena sayatan hanya pada area terbatas dan bisa menahan tekanan hingga 3 Bar (Gunawan, 2015).

Berbeda dengan penyayatan manual yang mengakibatkan tipisnya dinding bambu bagian dalam yang tidak merata. Pecahnya dinding bambu ditunjukkan pada gambar 8 berikut ini. Fokus amatan pada bagian ini adalah pada waktu pembuatan alur yang bertujuan menekan waktu proses pengawetan. Dengan metode lama rata - rata waktu untuk membuat alur ditunjukkan pada tabel 1. Rerata waktu pembuatan alur pada bambu dengan diameter $12-13,7 \mathrm{~cm}$ dengan pahat manual adalah 3,34 menit, waktu yang dibutuhkan untuk pra dan pasca pemahatan adalah 1 menit sehingga rerata waktu proses pemahatan adalah 5 menit 34 detik. Dalam waktu 1 hari jam kerja adalah 7 jam yaitu dimulai jam 8:00 pagi hingga jam 12:00 kemudian istirahat 1 jam hingga jam 13:00 dilanjutkan hingga jam 16:00.

Waktu kerja efektif adalah 6 jam, sehingga dalam 1 jam dengan 1 orang tenaga kerja akan dihasilkan 11 batang bambu, sehingga dalam 1 hari kerja dihasilkan sebanyak 66 batang bambu. Untuk memaksimalkan kapasitas menara pengawetan yaitu 400 batang bambu, maka dalam pekerjaan ini dibutuhkan 6 orang tenaga kerja. Dengan upah tenaga kerja sesuai upah tahun 2018 adalah Rp. 80.000 per orang per hari maka untuk proses ini dibutuhkan biaya tenaga kerja sebesar Rp. 1.212 per batang bambu. Dengan hasil tersebut untuk meningkatkan kapasitas produksi salah satunya adalah dengan penggunaan alat bantu. Alat bantu yang dimaksud adalah alat pembuat alur. Hasil pembuatan alur dengan mesin ditunjukkan pada gambar 8 .

Kedalaman alur pada dinding dalam bambu adalah 3-4 $\mathrm{mm}$, bisa disesuaikan juga dengan ketebalan dinding bambu yang akan diawetkan hal itu terkait dengan jenis bambu yang akan diproses. Hasil penggunaan alat pembuat alur ditunjukkan pada tabel 2 berikut ini.

Rerata panjang bambu yang diawetkan $3,56 \mathrm{~m}$, diameter bambu adalah $131,5 \mathrm{~mm}$, ketebalan dinding bambu 13,15 mm. Hasil pencatatan waktu paling lama 1 menit 56 detik, dan paling cepat 1 menit 20 detik dengan rerata 1 menit 39 detik. Dengan asumsi proses yang sama pada pembuatan jalur cairan dengan cara manual, waktu persiapan dan pasca proses masing-masing 1 menit sehingga rerata waktu adalah 3 menit 39 detik.

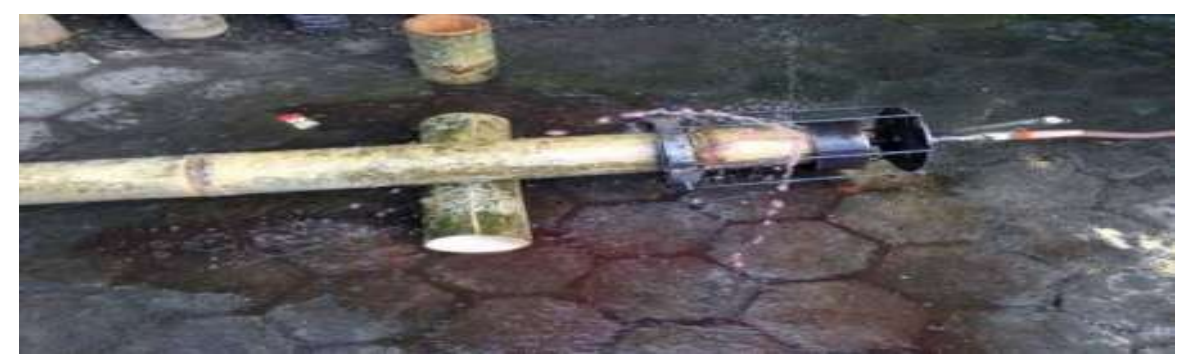

Gambar 7. Dinding Bambu Pecah Akibat Tekanan.

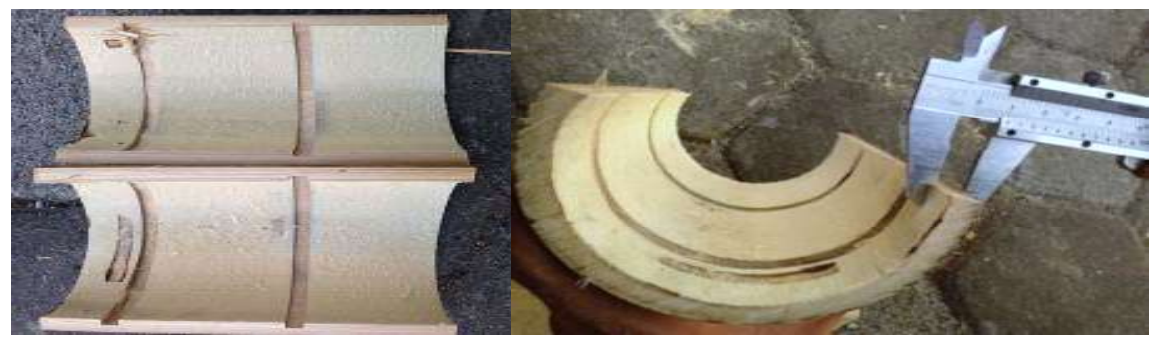

Gambar 8. Hasil Pemahatan Dengan Alat. 
Tabel 2. Pembuatan Alur dengan Mesin

\begin{tabular}{c|c|c|c|c|c|c|c}
\hline \multirow{2}{*}{ No } & \multirow{2}{*}{$\begin{array}{c}\text { Panjang } \\
\text { (mm) }\end{array}$} & \multicolumn{2}{|c|}{$\begin{array}{c}\text { Diameter Luar } \\
\text { (mm) }\end{array}$} & \multicolumn{2}{c|}{$\begin{array}{c}\text { Tebal Daging } \\
\text { Bambu (mm) }\end{array}$} & $\begin{array}{c}\text { Hasil } \\
\text { Pemahatan } \\
\text { (mm) }\end{array}$ & $\begin{array}{c}\text { Waktu } \\
\text { (menit) }\end{array}$ \\
\cline { 3 - 6 } & & Pangkal & Ujung & Pangkal & Ujung & $3-4$ & $1: 37$ \\
\hline 1 & 3600 & 125 & 109 & 12,5 & 10,9 & $3-4$ & $1: 20$ \\
3 & 3450 & 135 & 118 & 13,5 & 11,6 & $3-4$ & $1: 26$ \\
4 & 3540 & 130 & 113 & 13 & 11,2 & $3-4$ & $1: 45$ \\
5 & 3560 & 132 & 115 & 13,2 & 11,4 & $3-4$ & $1: 36$ \\
6 & 3650 & 133 & 116 & 13,3 & 11,2 & $3-4$ & $1: 50$ \\
7 & 3460 & 137 & 120 & 13,7 & 12,1 & $3-4$ & $1: 30$ \\
8 & 3680 & 135 & 118 & 13,5 & 11,6 & $3-4$ & $1: 56$ \\
9 & 3500 & 126 & 109 & 12,6 & 10,7 & $3-4$ & $1: 42$ \\
10 & 3650 & 134 & 117 & 13,4 & 11,7 & $3-4$ & $1: 50$ \\
\hline
\end{tabular}

Tabel 3. Hasil Percobaan Pemasangan Nosel Boucherie - Morisco Modifikasi Pada Bambu.

\begin{tabular}{c|c|c}
\hline No. & Diameter Luar $(\mathbf{m m})$ & $\begin{array}{c}\text { Waktu } \\
\text { (menit) }\end{array}$ \\
\hline 1 & 125 & $10: 05$ \\
2 & 135 & $10: 50$ \\
3 & 130 & $11: 35$ \\
4 & 132 & $10: 45$ \\
5 & 133 & $10: 25$ \\
6 & 128 & $11: 07$ \\
7 & 137 & $10: 15$ \\
8 & 135 & $10: 25$ \\
9 & 126 & $11: 45$ \\
10 & 134 & $11: 05$ \\
\hline \multicolumn{2}{c}{} \\
\hline
\end{tabular}

Dengan kenaikan performa hasil pemrosesan bambu untuk satu mesin dan satu orang tenaga kerja dalam 1 jam dihasilkan 17 batang bambu atau meningkat $54,5 \%$ dengan hasil total dalam satu hari adalah 102 batang bambu.
Jika menggunakan pendekatan kapasitas maksimal menara cukup dibutuhkan 4 orang tenaga kerja untuk mengerjakanya sehingga biaya tenaga kerja yang timbul dengan proses ini adalah Rp. 785. 


\subsection{Pemasangan Alat}

Pemasangan alat atau nosel pada pengawetan bambu sistem Boucherie Morisco sering menjadi keluhan pengerajin, pada nosel versi terdahulu tersebut pemasangan alat berdasarkan hasil wawancara dengan pemilik usaha membutuhkan waktu 15 hingga 25 menit bahkan beberapa kali sampai 60 menit hanya untuk pemasangan dan membetulkan jika ada kebocoran yang terjadi hingga proses pemasukan cairan berjalan dengan lancar, hal tersebut yang menyebabkan keengganan menggunakan alat lebih lanjut.

Selain itu kegagalan dalam pemasangan sering terjadi antara lain adalah bocornya instalasi akibat kurang seragamnya pengencangan tiga titik pada alat tersebut, kerataan ujung bambu karena hasil pemotongan yang tidak rapi. Hal ini yang akhirnya menjadi alasan pelaku usaha untuk tetap menggunakan metode Vertical Soak Diffusion (VSD) untuk mengawetkan bambu. Hasil pengujian pemasangan alat pada bambu adalah sebagai berikut. Waktu yang dibutuhkan untuk memasang nosel pengawetan paling cepat adalah 10 menit 7 detik dan paling lama adalah 11 menit 45 detik rerata waktu pemasangan adalah 10 menit 46 detik. Hasil lengkap ditunjukkan pada tabel 3 .

Pemasangan dilakukan 1 orang. Dengan pendekatan tenaga kerja berjumlah 4 orang disesuaikan kebutuhan tenaga kerja untuk pembuatan alur, dalam 1 jam menghasilkan 20 bambu sehingga dalam 1 hari kerja dihasilkan 120 batang bambu, untuk memasang alat pada 400 bambu dibutuhkan waktu 3 hari kerja lebih 2 jam atau dalam 4 hari dihasilkan pemasangan 480 batang bambu.
Dengan perhitungan tersebut biaya tenaga kerja pemasangan Total biaya tenaga kerja untuk 4 orang selama 4 hari adalah Rp. 1.280.000 sehingga biaya tenaga kerja untuk pemasangan alat adalah Rp. 2.666 perbatang bambu.

\subsection{Proses Injeksi Cairan Pengawet}

Proses injeksi bambu menggunakan rangkaian alat yaitu nosel dan tabung pengawetan. Tabung pengawetan ini sudah dimodifikasi sehingga bisa digunakan dilokasi penebangan. Keunggulan penggunaan tabung pengawetan ini berdasarkan beberapa percobaan masih bisa digunakan untuk pengawetan bambu setelah 10 hari pasca penebangan. Hal tersebut sangat menguntungkan karena selama ini kendala dalam mengawetkan bambu adalah rentang waktu kedatangan bambu dari waktu penebangan yang tidak menentu, hal tersebut disebabkan atara lain jarak dari tempat pengumpulan atau sulitnya medan tempat tumbuhnya bambu.

Seperti diketahui bahwa di pulau Jawa hingga saat ini belum ada perkebunan bambu yang diusahakan dengan hasil bambu dalam jumlah besar. Dengan semakin lama jarak antara waktu tebang dan waktu pengawetan akan berpengaruh terhadap kematian jaringan bambu, daging bambu akan semakin mengeras akibatnya adalah cairan tidak mampu lagi menembus atau masuk ke dalam jaringan tersebut. 
Tabel 4. Pengaliran Cairan ke Dalam Bambu

\begin{tabular}{c|c|c|c|c|c|c}
\hline \multirow{2}{*}{ No } & \multirow{2}{*}{$\begin{array}{c}\text { Panjang } \\
(\mathbf{m m})\end{array}$} & \multicolumn{2}{|c|}{$\begin{array}{c}\text { Diameter Luar } \\
(\mathbf{m m})\end{array}$} & \multicolumn{2}{c|}{$\begin{array}{c}\text { Tebal Daging Bambu } \\
(\mathbf{m m})\end{array}$} & $\begin{array}{c}\text { Waktu } \\
\text { (menit) }\end{array}$ \\
\cline { 3 - 6 } & & Pangkal & Ujung & Pangkal & Ujung & \\
\hline 1 & 3600 & 125 & 109 & 12,5 & 10,9 & $1: 10$ \\
2 & 3450 & 135 & 118 & 13,5 & 11,6 & $1: 06$ \\
3 & 3540 & 130 & 113 & 13,0 & 11,2 & $1: 11$ \\
4 & 3560 & 132 & 115 & 13,2 & 11,4 & $1: 12$ \\
5 & 3450 & 133 & 116 & 13,3 & 11,2 & $1: 08$ \\
6 & 3675 & 128 & 111 & 12,8 & 10,9 & $1: 18$ \\
7 & 3460 & 137 & 120 & 13,7 & 12,1 & $1: 10$ \\
8 & 3680 & 135 & 118 & 13,5 & 11,6 & $1: 20$ \\
9 & 3500 & 126 & 109 & 12,6 & 10,7 & $1: 10$ \\
10 & 3650 & 134 & 117 & 13,4 & 11,7 & $1: 17$ \\
\hline
\end{tabular}

Tabel 5. Ringkasan Proses Pengawetan

\begin{tabular}{c|c|c|c|c}
\hline No. & Komponen Pekerjaan & $\begin{array}{c}\text { Biaya Tenaga } \\
\text { Kerja / Bambu } \\
\text { (Rp.) }\end{array}$ & $\begin{array}{c}\text { Jumlah } \\
\text { Tenaga } \\
\text { Kerja }\end{array}$ & $\begin{array}{c}\text { Hasil } \\
\text { Dalam } \\
\text { 1 Hari }\end{array}$ \\
\hline 1 & Pembuatan alur dalam & 752 & 4 & 408 \\
2 & Pemasangan pada nosel & 2.667 & 4 & 120 \\
3 & Pengaliran cairan & 445 & 4 & 720 \\
\hline
\end{tabular}
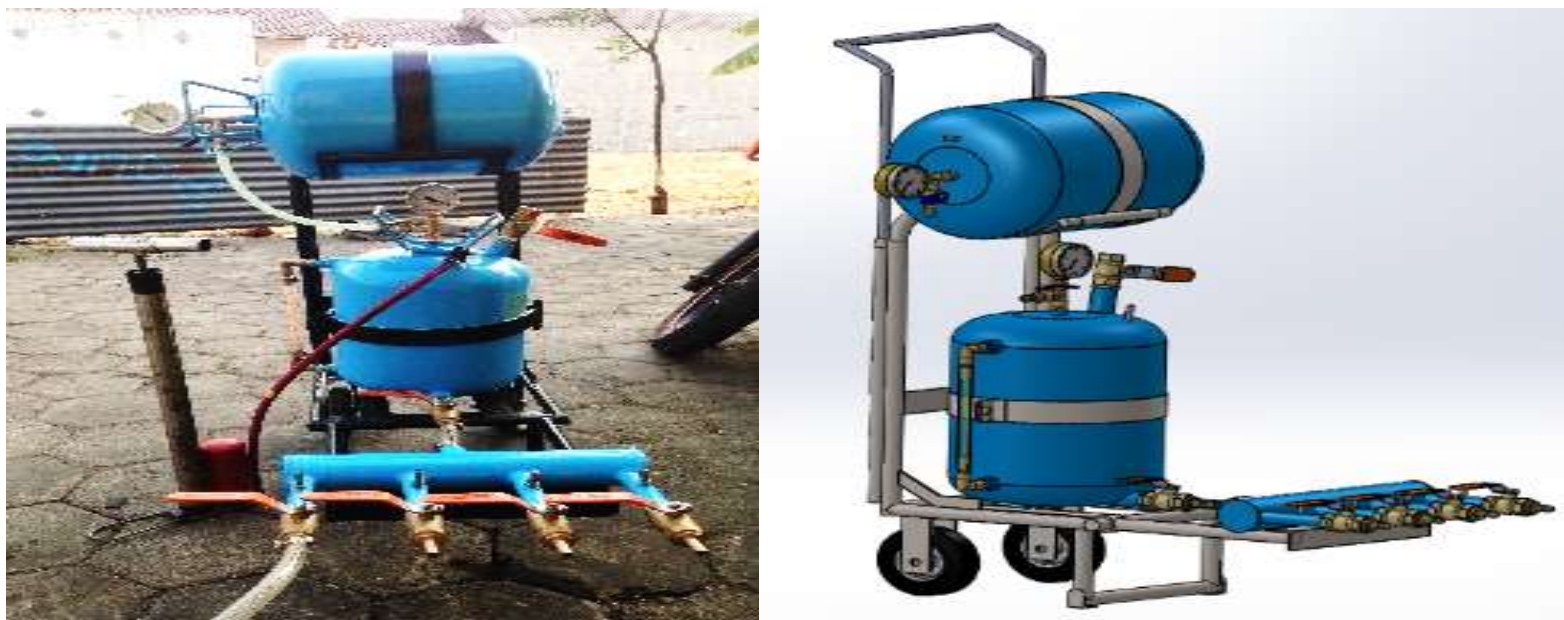

Gambar 9. Tabung Pengawetan Bambu Boucherie - Morisco Modifikasi. 
Hal itu sangat mempengaruhi hasil dari pengawetan bambu karena cairan tidak terserap sempurna pada model pengawetan VSD. Alat pengawetan dengan tabung bertekanan Metode Boucherie - Morisco Modifikasi ditunjukkan pada gambar 9 Tabung Pengawetan Bambu Boucherie Morisco Modifikasi.

Dengan kemudahan dan jaminan lancarnya proses pengawetan bambu, diharapkan akan meningkatkan jumlah bambu yang bisa diawetkan dalam satu hari dan memperoleh hasil yang maksimal. Selain itu pemenuhan kebutuhan bambu akan seimbang dengan permintaan dari konsumen.

Hasil uji coba dengan rerata panjang bambu $3556.5 \mathrm{~mm}$, rerata diameter bambu $131,5 \mathrm{~mm}$, rerata tebal dinding bambu 13,15 mm didapatkan waktu pengaliran cairan tercepat 1 menit 6 detik, dan terlama 1 menit 20 detik dengan rerata 1 menit 12 detik. Dengan hasil tersebut didapatkan kecepatan pengaliran adalah $0,05 \mathrm{~m} / \mathrm{det}$ atau untuk mengalirkan cairan pada bambu dengan diameter $13 \mathrm{~cm}$ sepanjang $1 \mathrm{~m}$ dibutuhkan waktu 20 detik. Hasil pencatatan waktu penetrasi cairan ke dalam bambu ditunjukkan pada tabel 4 .

Dengan asumsi sama dengan proses sebelumnya proses ini bisa dikerjakan 4 orang, dalam 1 hari untuk mengerjakan bambu dengan panjang $6 \mathrm{~m}$ dibutuhkan waktu 120 detik atau 2 menit. Dengan memaksimalkan hasil dalam satu hari akan didapatkan hasil bambu awetan sebanyak 720 batang, dengan asumsi proses dikerjakan 4 orang maka biaya yang timbul untuk proses pengaliran cairan adalah Rp. 445 / batang bambu.
Dari pembahan diatas proses pengawetan yang dilakukan dengan urutan rangkaian sebagai berikut :
a. Pembuatan Alur Dalam.
b. Pemasangan Nosel.
c. Pengaliran Cairan.

Biaya tenaga kerja yang timbul, waktu, dan tenaga kerja yang dibutuhkan untuk proses pengawetan bambu ditunjukkan pada tabel 5. Dengan terget Bambu sejumlah 400 batang dengan tenaga kerja sejumlah 4 orang maka waktu yang dibutuhkan untuk proses pengawetan adalah 6 hari dengan biaya tenaga kerja adalah Rp. 3.864 per batang untuk bambu petung diameter rata - rata $131,5 \mathrm{~mm}$ dan panjang $6000 \mathrm{~mm}$. Waktu pengawetan dengan proses VSD adalah 14 hari bisa dipersingkat menjadi 5 hari dengan metode Boucherie - Morisco Modifikasi. Atau dengan kata lain dalam waktu yang sama bisa dihasilkan bambu sejumlah 1.120 batang bambu.

Dengan demikian proses pengawetan yang dilakukan dengan metode VSD yang semula dalam satu bulan hanya menghasilkan 800 batang bambu petung dengan penerapan teknologi baru ini akan meningkatkan hasil sebanyak 2400 batang bambu. Selain itu biaya investasi untuk pembangunan menara pengawet sebesar Rp. 55.000.000 bisa dialihkan untuk pengadaan peralatan dan membangun fasilitas gudang yang biayanya lebih murah dengan jumlah set alat yang lebih banyak. Resiko pekerjaan diketingian yang sebelumnya dihadapi para pekerja bisa dihindarkan dengan menggunakan pengawetan sistem Boucherie - Morisco modifikasi. 


\section{KESIMPULAN}

1. Pengawetan Bambu dengan metode Boucherie-Morisco modifikasi bisa menjadi alternatif untuk meningkatkan hasil produksi bambu awetan. Beberapa kesulitan dalam proses produksi bisa menjadi bahan dalam mengembangkan sistem pengawetan bambu modern.

2. Biaya tenaga kerja bisa ditekan dan bisa Jaminan keselamatan bagi SDM juga lebih tinggi dengan sistem BoucherieMorisco karena tidak lagi harus naik ke menara yang tinggi. mengefektifkan kinerja SDM dengan hasil produksi yang lebih terjamin.

3. Dengan mengembangkan semangat technopreneurship dan kemitraan dengan usaha kecil menengah diharapkan permasalahan terkait produksi yang selama ini dihadapi UKM bisa teratasi dengan cara yang sempurna. Kerjasama tersebut juga akan mempermudah komunikasi dan penelitian yang pastinya akan bermanfaat untuk akademisi dan penggiat UKM.

\section{DAFTAR PUSTAKA}

Afandi, M.M. Perancangan Dan Pembuatan Nozzle Pengawetan Bambu Pengembangan Metode Boucherie Morisco Untuk Industri Kecil. Tugas Akhir Jurusan Teknik Mesin Fakultas Teknologi Industri Universitas Islam Indonesia, 2015.

Gunawan, R. Perancangan dan Pembuatan Alat Pembuat Alur Dalam Sebagai Alat Bantu Pengawetan Bambu Metode Boucherie-Morisco. Tugas Akhir Jurusan Teknik Mesin Fakultas Teknologi Industri Universitas Islam Indonesia., 2015.

Liese, W and Satish, K. Bamboo Preservation Compendium. Indian Bamboo Resource and Technology., 2003.

Link, A. N., \& Siegel, D. S. Innovation, entrepreneurship, and technological change. Oxford; New York: Oxford University Press., 2007.

Mulyadi. Akuntansi Biaya, Edisi 5. Yogyakarta: Aditya media., 2000.

Mulyadi. Akuntansi Biaya, Edisi 10, Cetakan ke-7. Unit Penerbit dan Percetakan YKPN: Yogyakarta., 2005. 
Shelters, D. Start-up guide for the technopreneur: financial planning, decision making, and negotiating from incubation to exit. Singapore; Hoboken, NJ: John Wiley \& Sons Singapore Pte. Ltd., 2013.

SNI 03-3233-1998. Pengawetan Kayu untuk Bangunan Rumah dan Gedung. Badan Standardisasi Nasional, Jakarta., 1998.

Sulthoni, A. Suatu Kajian tentang Pengawetan Bambu Secara Tradisional untuk Mencegah Serangan Bubuk. Disertasi Doktor, Universitas Gadjah Mada, Yogyakarta (tidak diterbitkan)., 1998.

Supriyono. Akuntansi Biaya, Buku Satu. Yogyakarta: BPFE., 2000.

Syarif, F.R. Perancangan dan Pembuatan Tabung Pengawet Bambu Pengembangan Metode BoucherieMorisco Untuk Industri Kecil. Tugas Akhir Jurusan Teknik Mesin Fakultas Teknologi Industri Universitas Islam Indonesia., 2015.

Zuraida, S., \& Larasati, D. The Assessment of Marginal Prevention Costs on Bamboo Preservation Method. The 5th Sustainable Future for Human Security (SustaiN 2014), 28, 789 798., 2015. 